\title{
Bastilhas de pobres e prisões da democracia
}

\section{Uma reflexão sobre um trade-off entre liberdade e (auto)controle ${ }^{1}$}

\author{
Dario Melossi* \\ https://orcid.org/0000-0002-3058-8701
}

Procuro, a seguir, transpor o argumento em que está baseada a reconstrução das origens da instituição prisional, apresentada há muito tempo, juntamente com Massimo Pavarini, em Cárcere éábrica: as origens do sistemapenitenciário (séculos XVI-XIX) ${ }^{2}$, e em meu ensaio sobre conceitos de Estado e controle social em The state of social control: a sociological study of concepts of state and social control in the making of democracy (Melossi, 1990). O interesse deste estudo está, creio eu, em demonstrar que existe uma forte relação entre a ideia de autocontrole (ligada à invenção da prisão) - ao invés daquela de autogoverno, ligada à noção de contrato social - e a ideia moderna de Estado. Tal relação, por sua vez, está ligada a duas formas de pensar a função do encarceramento, representadas pelas duas imagens da Bastilha e da bastilha ${ }^{3}$ dos pobres (ver abaixo).

\section{Universidade de Bolonha, Bolonha, Itália.}

1. Este ensaio é baseado em uma palestra proferida na Reunião Anual da RCSL/sDJ, "Direito e cidadania além do Estado”, em Lisboa/Portugal, a 11 de setembro de 2018, e em palestras proferidas na Escola de Verão "Antigone” em Torino/Itália, em 24 de setembro de 2018, e na Universidade de Winchester/ Reino Unido, em $1^{\circ}$ de novembro de 2018. Além disso, foi desenvolvido durante estadias prolongadas no Centro para o Estudo de Direito e Sociedade da Universidade da Califórnia, Berkeley. Tradução e revisão do inglês por Mariana Chies-Santos (doutora em sociologia, PPGS/Ufrgs) e Pedro Benetti (doutor em ciência política, Iesp/UERJ), ambos pesquisadores com bolsa de pós-doutorado no Núcleo de Estudos da Violência da Universidade de São Paulo.

2. Reafirmado recentemente em Melossi e Pavarini (2018). Ver, em particular, minha Introdução à nova edição (Melossi, 2018).

3. Nota dos Tradutores: Quando a palavra Bastilha aparecer com letra maiúscula, diz respeito à prisão célebre durante a Revolução Francesa; e, com letra minúscula, às "bastilhas” dos pobres. 
Quando, no início dos anos 1970, Massimo Pavarini e eu - trabalhando em Cárcere e fábrica (1977) - começamos a olhar para a história da instituição prisional, partilhávamos de uma visão comum sobre a prisão e a penalidade como "locais de repressão", especialmente a repressão à luta política. Na sequência dos anos 1960, o uso "repressivo" da prisão parecia uma realidade óbvia, já que víamos “camaradas", líderes de movimentos sociais e sindicalistas, presos. Foi grande, então, a nossa surpresa quando começamos a reunir estatísticas sobre as taxas de encarceramento ${ }^{4}$. Por volta dos anos 1970, estávamos num ponto muito baixo de uma tendência decrescente no uso da prisão (e isso não só na Itália) - tendência também decrescente no uso das prisões como espaços de repressão política. Como explicar esse aparente paradoxo? Na verdade, 1970 marcou o clímax da luta política e, historicamente - descobrimos mais tarde -, os picos de força política e econômica da classe trabalhadora foram normalmente caracterizados, ao mesmo tempo, por alto conflito político e baixas taxas de encarceramento. Isso pode ser representado, muito esquematicamente, na Figura 1, em que as taxas de encarceramento da Itália e dos Estados Unidos são sobrepostas a uma representação teórica de longo prazo do extenso ciclo econômico, expresso pela curva sinusoidal. Tal ciclo econômico marca também os pontos históricos baixos e altos da força da classe trabalhadora. Os contextos históricos que marcam a força da classe trabalhadora estão geralmente ligados às baixas taxas de encarceramento. Em tais conjunturas históricas, na verdade, as taxas de desemprego são baixas e os conflitos sociais são altos. Todos aqueles que querem procurar um emprego podem encontrá-lo, e as organizações políticas e laborais da classe trabalhadora têm um poder considerável. Esse poder é geralmente combatido pelos representantes políticos dos interesses e necessidades do capital (seja de capital público ou privado), de modo que os militantes políticos e trabalhistas possam enfrentar os rigores de uma prisão que, no entanto, é usada com parcimônia. Mais tarde, porém, o poder político do capital volta a prevalecer maciçamente. Daí em diante, ondas de novos trabalhadores são recrutadas através da migração ou através do emprego em setores arruinados da classe média baixa e de antigos setores independentes (como artesãos e pequenos produtores rurais). Esses novos indivíduos recrutados como mão de obra encontram nas instituições sociais como as prisões as estruturas que induzem sua adaptação a um contrato social restabelecido e reforçado (Rusche e Kirchheimer, 1939; Melossi, 2008, pp. 275-300). Se isso pode aparecer, em termos da ideologia da “prisão" e das "ciências penais", sob o pretexto de "reabilitação", na prática da prisão e de outras instituições semelhantes, parece como treinamento para adquirir um hábito de obediência e de subordinação (Melossi, 2020).

4. Exploro mais esse ponto em outro trabalho (Melossi, 2008, pp. 275-300). 
FIGURA 1

Taxa de encarceramento nos Estados Unidos e na Itália, por 100 mil habitantes, 1863-2015

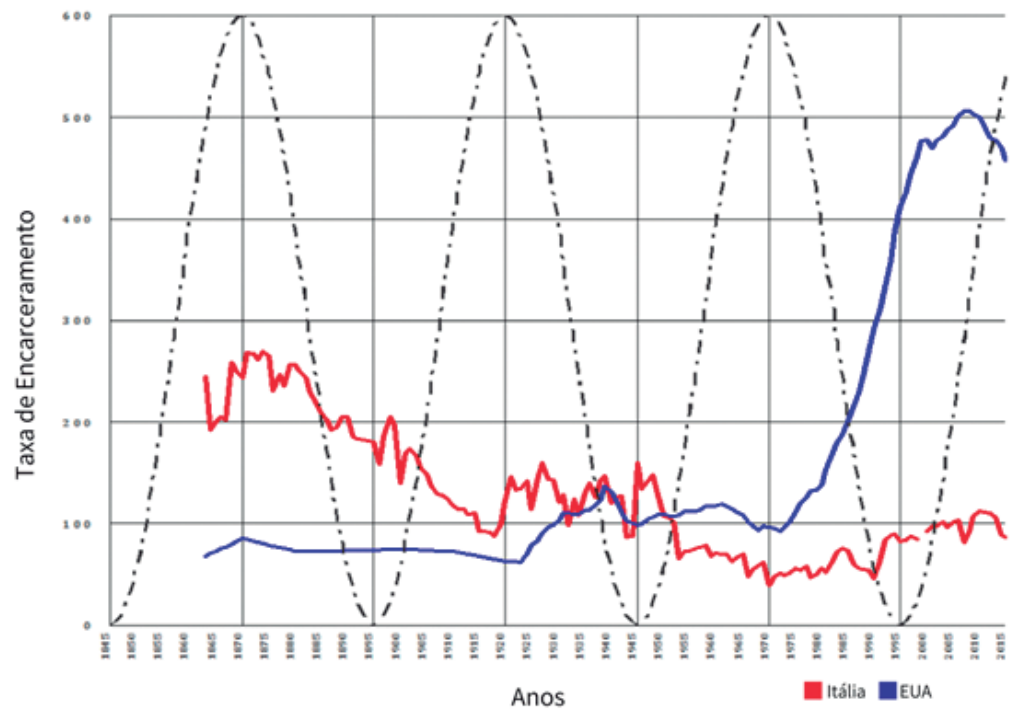

Fonte: Compilado usando dados do Istat e do Bureau of Justice Statistics. (A curva senoidal representa a imagem esquemática dos ciclos econômicos de longo prazo).

Há, portanto, um "duplo uso" da prisão na perspectiva do conflito de classes: por um lado, como uma ferramenta de repressão política, que podemos chamar de Bastilha, e que está ligada à tirania ou, de qualquer maneira, ao ressurgimento de episódios tirânicos dentro de políticas autodenominadas liberal-democráticas, afetando principalmente membros engajados da classe média e/ou militantes políticos e trabalhistas que são, ao mesmo tempo, aspirantes a membros de elites políticas (como nos anos 1970). Por outro lado, ao contrário, a prisão é um instrumento de “disciplina”, ligado a projetos de transformação política e social (não alheio, muitas vezes, a aspirações políticas democráticas ou mesmo revolucionárias) e essencialmente dirigido a membros das classes populares. Não é de admirar, então, que as casas de trabalho inglesas estabelecidas pela Poor Law, em 1834, tenham sido imediatamente renomeadas, pelo proletariado inglês, como bastilles de poor law (Melossi \& Pavarini 1977, p. 76). Assim, existem Bastilhas tradicionais e bastilhas de gente pobre.

Além disso, essa dupla identidade da instituição prisional está geralmente ligada a uma dicotomia questionável, imaginária e ideológica da teoria política: por um lado, a imagem de um Estado "forte" - que aparentemente tem por base a tirania e a repressão política -, e, por outro lado, aquela de um Estado "fraco" - que aparentemente tem por base a democracia e o respeito pelos direitos humanos, civis e políticos. Enquanto trabalhava em The state of social control (Melossi, 1990), no 
entanto, pareceu-me claro o quão estereotipada e imprecisa era esta última imagem do Estado. Durkheim, nas palestras reunidas em Liçôes de sociologia (1898-1900), já havia ressaltado, basicamente, que a democracia atribui ao Estado uma modalidade de governo muito mais eficaz e mais forte, pois ajuda a construir a comunicação entre as elites políticas e as massas (nesta ordem). Conflitos que, no passado, seriam administrados por meio de medidas coercitivas, agora, podem ser governados pelo controle da opinião pública. As elites políticas teriam, é claro, que dar algo em troca $\mathrm{e}$, a contragosto, ceder às demandas dos cidadãos por direitos humanos e políticos básicos. Então, haveria uma espécie de "trade-off".

Muito antes de Durkheim, porém, Cesare de Beccaria, no livro Dos delitos e das penas [1764], já havia subvertido profundamente essa imagem estereotipada do Estado. Em capítulos bastante perspicazes dedicados a "como prevenir delitos", verdadeiro resumo da sabedoria do Iluminismo, Beccaria faz uma distinção crucial entre o cidadão pertencente a uma monarquia esclarecida (mais tarde, talvez, uma República, ou mesmo uma Democracia!) e o tema da tirania. Ele escreve:

Os homens escravos são mais voluptuosos, mais libertinos e mais cruéis do que os homens livres. Estes meditam sobre as ciências e sobre os interesses da nação, veem os grandes objetos, e os imitam, mas aqueles, satisfeitos com o dia presente, procuram, no tumulto da libertinagem, uma distração para o aniquilamento em que se encontram. Afeitos à incerteza em tudo, o êxito dos seus crimes torna-se-lhes problemático; favorecendo a paixão que os determina (Beccaria, 1999, p. 128).

A única coisa exigida do sujeito que vive na tirania é, de fato, a aceitação de sua própria servidão política: isso pode muito bem vir conjuntamente com uma licença às questões morais. Na verdade, essa licença pode até ser útil para fins governamentais: Feste, Farina e Forca - Festas, Farinha (para o pão!) e a Forca - foram os "três F's" com os quais Fernando II, da Casa dos Bourbons, governaria o Reino das Duas Sicílias (ou seja, o sul da Itália) antes da unificação! Pelo outro lado, o sujeito que vive na democracia tem que dar o seu consentimento, ou seja, deve concordar com os seus dirigentes políticos, e isso é mais complexo e enfadonho! Portanto, parece-me que a chave para tentar chegar a um entendimento mais completo do que Beccaria quis dizer está no início do próximo capítulo da obra Dos delitos e das penas, na qual Beccaria começa o parágrafo "Das ciências" ainda perguntando "Você quer prevenir crimes?", e ele responde com o que é, em minha opinião, uma das grandes declarações do Iluminismo: Fate che i lumi accompagnino la libertà (Fazei com que as luzes acompanhem a liberdade). Por que uma liberdade iluminada é necessária para prevenir crimes? 
Um teórico político estadunidense, Thomas Dumm (1987), pode nos ajudar a entender melhor essa afirmação de Beccaria. Ao adaptar a análise de Foucault à realidade norte-americana (em que, no entanto, acredito que funciona ainda melhor do que na europeia), Dumm vê uma relação entre o mecanismo de autocontrole e o mecanismo de autogoverno. Dumm inicia a análise a partir da famosa viagem de Alexis de Tocqueville aos Estados Unidos, para onde foi enviado em 1831 pela Coroa francesa, juntamente com Gustave de Beaumont, para descrever os fabulosos novos "sistemas penitenciários" (Beaumont e Tocqueville, 1833). Nessa viagem, entretanto, Tocqueville reuniu os materiais para escrever o que, ao mesmo tempo, é um dos textos e descrições fundamentais da sociedade norte-americana e, mais ainda, do conceito de democracia, Democracia na América (Tocqueville, 1835). E Dumm se pergunta, essencialmente, como é possível que aqueles que foram à América do Norte para escrever sobre a prisão voltassem escrevendo, não apenas um livro sobre democracia,

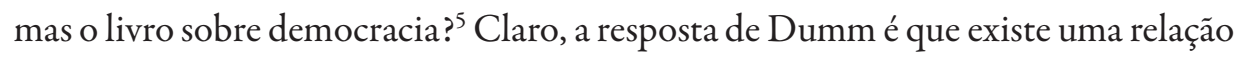
profunda entre esses dois aspectos, entre a descoberta do modelo penitenciário e o surgimento do conceito de democracia nos Estados Unidos. Em Democracy and punishement, Dumm afirma:

Acho [...] que a emergência do modelo penitenciário nos Estados Unidos correspondeu a um projeto constitutivo de democracia liberal. Ou seja, o sistema penitenciário formava o projeto epistemológico da democracia liberal, criando condições de conhecimento de si e do outro, que se destinavam a constituir o sujeito político necessário à realização da prática dos valores liberais e democráticos. O projeto americano, um sistema de autogoverno, significava não apenas o estabelecimento de um sistema de governo representativo com o mais amplo direito ao voto possível, mas também o estabelecimento de instituições que encorajassem a interiorização dos valores democráticos liberais, a criação de indivíduos que aprenderiam a se governarem (Dumm, 1987, p. 6).

O ponto de partida de Dumm é, claro, a brilhante leitura de Michel Foucault de Panóptico, de Jeremy Bentham, em Vigiar e punir (Foucault, 1975). No projeto do Panóptico - estabelecimento prisional construído em torno de uma torre de vigilância que permite ao diretor inspecionar os presos, mas que protege o diretor, por meio de um sistema de venezianas, de ser visto pelos mesmos -, o sistema de fiscalização resultante não só persegue uma meta utilitarista, ao poupar dinheiro e

5. Além de ser verdadeiramente surpreendente, para quem visita os Estados Unidos hoje, que, apenas trinta ou quarenta anos após a Independência, Tocqueville já foi capaz de captar aspectos da cultura norte-americana que ainda hoje são absolutamente verdadeiros. 
recursos. Sendo um sistema através do qual poucos podem controlar muitos, cria também uma situação em que o preso, com medo de ser vigiado, mas sem saber se está realmente sendo vigiado, desenvolve lentamente sua própria “autoinspeção” ou autocontrole. Portanto, pelo menos em teoria, o "projeto" do Panóptico pode ser visto como uma máquina testada e comprovada para a criação do que, muitos anos depois, Sigmund Freud ${ }^{6}$ chamará de superego, ou, pelo menos, o superego daqueles que não o desenvolveram totalmente na infância.

Dumm, portanto, lendo Foucault, encontra uma relação entre a criação de indivíduos capazes de autocontrole e a criação de um sistema político e social baseado no autogoverno. A ideia, em outras palavras, é de que apenas aqueles que são capazes de autocontrole podem participar de um autogoverno livre e racional. Benjamin Rush, um dos Quakers considerados pais fundadores da independência americana, falará até da criação de "máquinas republicanas": os indivíduos que são "formados" por essas novas instituições devem ser transformados em "máquinas republicanas" para funcionar dentro da nova sociedade republicana, uma sociedade baseada no autogoverno. A "persuasão amigável”, como William Penn ${ }^{8}$ e os Quakers a chamavam, é, ao mesmo tempo, a persuasão Quaker, a confissão Quaker, mas é também esse novo estilo de governo que Penn se esforça para inaugurar e colocar em prática. Então, o ponto realmente interessante, na minha opinião, e que já havia sido captado por Beccaria naqueles parágrafos, é essa espécie de trade-off, de troca, de modo que o lugar da opressão por excelência seja também o lugar da construção desses laços internos, que tornam a liberdade externa possível. Ou, pelo menos, essa era a teoria, o "projeto" de tudo!

Há uma passagem famosa do jovem Marx que acho que vale a pena mostrar, porque expressa de forma extremamente concisa algo muito parecido com o que

6. Nota dos Tradutores: Os textos de Freud, Lacan e Marx que haviam sido traduzidos anteriormente para o português foram utilizados nesta tradução e estão referenciados ao final do ensaio. Em relação às obras em que ainda não há edição em português, as traduções foram realizadas a partir do texto do próprio autor.

7. Os Quakers se refeririam ao princípio da "persuasão amigável” que, por um lado, é literalmente a descoberta de uma sociedade baseada no consenso, porque quem é capaz de autocontrole é também quem será capaz de construir uma ordem social baseada no consenso. Mas, ao mesmo tempo, o princípio é também uma referência à sociedade Quaker, porque persuasão significa confissão, e essa persuasão é amigável porque os Quakers se autodenominam “a Sociedade dos Amigos”, o nome que os Quakers dão à sua confissão, a sua organização.

8. As reformas de William Penn em 1681, muito antes de Leopold I, da Toscana, em 1786, prescreveram a eliminação da pena de morte e da tortura e a generalização da prisão. Também nisso as Comunidades Protestantes da América do Norte pareciam ter precedido as políticas mais avançadas do Iluminismo europeu (esta foi a tese do mentor de Max Weber, Georg Jellinek, em sua Declaração dos Direitos do Homem e dos Cidadãos (1895), na qual Jellinek afirmou a importância da visão de mundo protestante para o estabelecimento das declarações dos direitos do homem nos novos estados americanos e, posteriormente, na Revolução Francesa). 
estamos tentando dizer aqui. Na introdução de Crítica da Filosofia do Direito de Hegel, de 1844, Marx, em um ponto, falando da Reforma Protestante, escreve:

Sem dúvida, Lutero venceu a servidão por devoção porque pôs no seu lugar a servidão por convicção. Quebrou a fé na autoridade porque restaurou a autoridade da fé. Transformou os padres em leigos, transformando os leigos em padres. Libertou o homem da religiosidade exterior, fazendo da religiosidade o homem interior. Libertou o corpo dos grilhões, prendendo com grilhões o coração (Marx, 2010, p. 152).

Aparece aqui uma concepção de Marx, mas também de Weber (1904-1905) em $A$ ética protestante e o espírito do capitalismo: com o Protestantismo, em certo sentido, a estrutura da igreja amalgama-se, liquefaz-se e se dilui dentro da sociedade como um todo, mas consequentemente transformando também a sociedade e assim criando a possibilidade de relações baseadas no consenso, na convicção, ao invés do princípio autoritário da hierarquia 9 .

Parece-me, voltando a Beccaria, que tudo isso está por trás desta oposição, que Beccaria coloca no centro do trecho "Prevenção do crime": entre os escravos, que são mais "voluptuosos" e "mais cruéis" do que homens livres, e aqueles que, ao contrário, "meditam nas ciências, meditam nos interesses da nação, veem grandes objetos e são inspirados por eles”. Estes últimos são aqueles capazes de expressar o autogoverno (em uma monarquia esclarecida, no tempo de Beccaria, mas, em sequência, da monarquia esclarecida à república e da república à democracia). São aqueles que pedem o consenso, a participação dos seus concidadãos e, portanto, também uma forma muito mais intensa de "controle". A persuasão amigável não é o tipo de controle que pode vir de fora, como Beccaria escreve, no parágrafo 45, sobre educação. Evitar fazer o mal não pode advir "da incerteza da ordem, que obtém apenas uma obediência simulada e momentânea" (Beccaria, 1764). Uma "obediência simulada e momentânea” não é a mesma coisa que um hábito de obediência! Se a ordem social é mantida apenas na base do medo e do comando do soberano, é uma ordem extremamente fraca e frágil: quando a ameaça é dirigida a outra pessoa, aquele que foi primeiro ameaçado não está mais sob nenhum tipo de controle. Se, em vez disso, o controle é um controle descentralizado, um controle baseado na participação independente e livre dos controlados, obviamente é um tipo de controle muito mais eficaz. Qual é o preço que a ordem social paga em troca? Para que prevaleça esse tipo de controle, deve preponderar uma ordem baseada no autogoverno, diríamos hoje, uma ordem

9. Um motivo semelhante é explorado por Octavio Paz em seu "Mexico and the United States" (Paz, 1985, pp. 355-376; Melossi, 2008, pp. 109-123). 
democrática. Então realmente uma ideia de troca, de trade-off, fundamentalmente, em que a escravidão se torna uma escravidão interna, mas, graças a essa escravidão interna - como mencionamos, basicamente a criação de uma espécie de "superego", em Sigmund Freud, ou uma espécie de "outro generalizado", nos termos menos patriarcais de George Herbert Mead (Freud, 1921; Mead, 1925) -, o self tem a possibilidade de participar de uma sociedade externa mais livre, a sociedade republicana, a sociedade democrática. Só é possível participar de uma sociedade mais livre na medida em que seja garantida a escravidão interna, baseada no autocontrole, nos princípios da "racionalidade" 10 .

Não é por acaso que introduzimos termos vagamente extraídos da psicanálise ${ }^{11}$. Algumas dessas ideias parecem lembrar as posições de um dos primeiros alunos e seguidores de Sigmund Freud: Paul Federn. Federn teve uma intuição genial no período revolucionário após a Primeira Guerra Mundial. Ele, na verdade, condenou as revoluções comunistas tentadas na Europa da época, porque dariam origem ao que chamou de Vaterlose Gesellschaften, "sociedades sem pai”, sociedades que negavam o princípio de autoridade corporificado na figura paterna, um princípio fortemente reverenciado pelos freudianos. Em movimento ainda mais brilhante, Federn comparou essas sociedades ao que se construía, ao mesmo tempo, no "novo mundo", um mundo de filhos que estavam abandonando seus pais, que não puderam, portanto, construir uma verdadeira civilização. Em 1930, Freud escreve:

Esse perigo é mais ameaçador onde os vínculos de uma sociedade são principalmente constituídos pelas identificações dos seus membros uns com os outros, enquanto que indivíduos do tipo de um líder não adquirem a importância que lhes deveria caber na formação de um grupo. O presente estado cultural dos Estados Unidos da América nos proporcionaria uma boa oportunidade para estudar o prejuízo à civilização, que assim é de se temer (Freud, 2019, p. 7.789$)^{12}$.

10. A respeito disso, ver: Horkheimer e Adorno (1944).

11. Lembramo-nos da famosa frase de Freud no final da trigésima primeira aula das Novas Palestras Introdutórias: "Onde estava o id, ali estará o ego. É uma obra de cultura - não diferente da drenagem do Zuiderzee” (Freud, 1996, p. 84) [O Zuiderzee é um golfo formado pelas águas do Mar do Norte no centro-norte dos Países Baixos, na Europa]. Esta ideia da racionalização dos instintos humanos como uma espécie de reclamação de terras aparecerá na Itália fascista no próprio título do livro dedicado pelo fascista ministro da Justiça Dino Grandi para comemorar o décimo aniversário da "Reforma Penitenciária”, Bonifica Umana (1941), um enorme livro brilhante cheio de ilustrações que, recordo-me, Massimo Pavarini costumava achar particularmente fascinante. Também apelou para a ênfase do fascismo na importância da economia rural e das "colônias penais agrícolas" para a ressocialização de prisioneiros.

12. Nas páginas introdutórias de seu "A coisa freudiana”, Jacques Lacan recontaria um episódio interessante da relação de Freud com os Estados Unidos: "É assim que o dito de Freud a Jung, de cuja boca o ouvi, quando, ambos convidados da Universidade Clark, avistaram o porto de Nova York e a célebre 
Em outras palavras, a situação de uma terra de imigrantes que deixaram seus "pais" para trás e que esperavam encontrar "irmandade" no Novo Mundo, da mesma forma que tentavam encontrá-la nas sociedades pós-revolucionárias (Federn, 1919, p. 598), era uma situação de "pobreza psicológica" que representava uma ameaça para a "civilização".

Sem dúvida, para Freud, essa situação constituía um perigo que ameaçava o "vínculo social" pai-filho, perpassando toda a hierarquia dos "grupos" sociais, da família ao Estado. Essa visão autoritária e hierárquica da ordem social estava na raiz da visão tradicional europeia de Estado. É claro que, nos anos críticos entre o século XIX e o XX, nem todos os europeus compartilhavam dessa visão. Em particular, não é por acaso que, em sua teoria da democracia, Hans Kelsen criticou profundamente tal visão do Estado a partir, exatamente, de uma revisão dos escritos de Freud sobre psicologia de massa e antropologia, de Totem e tabu à Psicologia de grupo e análise do ego (Freud, 1913 e 1921). Kelsen, em particular, foi crítico de uma ideia do Estado como o "autor" do controle social, de acordo com uma tendência antropomórfica de pensar o Estado "als eine Art, Makroanthropos, oder Uebermensch", que é o "portador" da lei, uma "personalidade ativa", que "faz" isso e aquilo, "organiza", "impõe”, “proíbe”, e às vezes até atribui recompensas e punições de várias naturezas (Kelsen, 1922). Um verdadeiro "grande pai" que na psicologia de massas, muitas vezes, tinha sido associado a uma pessoa real, o ditador de alguma forma sancionado por Deus (ver Psicologia de grupo e a análise do ego, de Freud) ${ }^{13}$. Kelsen pensava em democracia exatamente como uma "sociedade sem Estado", uma "sociedade de irmãos", uma "irmandade", uma fraternité, como na famosa trindade da Revolução Francesa (Melossi, 1990, pp. 86-91) ${ }^{14}$.

Na verdade, essa comparação entre a construção do comunismo e a construção de um "novo mundo" vai além de seu valor literário (exceto, é claro, para o destino ultra-autoritário, totalmente paternalista, mas obviamente desconhecido para Federn, daquelas sociedades pós-bolcheviques!). A emigração foi muitas vezes o resultado das agitações revolucionárias que sacudiam intermitentemente o "velho continente".

estátua que ilumina o universo - 'Eles não sabem que lhes estamos trazendo a peste' -, é-lhe devolvido como sanção por uma arrogância cuja antífrase e perfídia não extinguem seu brilho perturbador. A Nêmesis só precisou, para apanhar seu autor na cilada, tomá-lo ao pé da letra de seu dito. Seria de se temer que ela juntasse a ele uma passagem de volta na primeira classe" (Lacan, 1998, p. 404).

13. Certamente, Foucault (1978) contribuirá para questionar profundamente essa ideia tão autoritária, patriarcal e essencialmente fantasmagórica da ordem social como aquela envolvida no Estado.

14. Ver as reflexões de Carole Pateman, partindo da leitura destes mesmos textos de Freud, sobre a noção de fraternidade (irmandade) como noção de contrato social igualitário (daí a ideia de democracia de Kelsen, como vimos) mas entre irmãos, um contrato sobre a partilha do poder político e do controle sobre as mulheres (daí o que ela chama de "contrato sexual" (Pateman, 1988). 
A própria perseguição ao protestantismo radical foi frequentemente misturada com perseguição por razões sociais e políticas, visto que algumas das seitas protestantes geralmente seguiam os princípios do igualitarismo radical. E quando nossos cafo$n e^{15}$ do sul da Itália começaram a migrar para as Américas, sua ação foi vista, pelos feudatários locais do sul da Itália que perdiam mão de obra barata e empregados, como um ato de desobediência comparado ao de tomar o caminho das montanhas, tornando-se bandidos! (Teti, 1993).

Em meu livro The state of social control: A sociological study of concepts of state and social control in the making of democracy (Melossi, 1990), afirmo que, no decorrer do início do século Xx, uma nova ideia de ordem social emergiu lentamente nos Estados Unidos, uma ideia de ordem social baseada em uma tradição muito menor do que a do Estado, pertencendo às ciências sociais e não à filosofia política. Uma visão de ordem social que já não descia dos céus da filosofia política em uma sociedade ainda pré-democrática, na qual um conhecimento essencialista do "Estado" foi pressionado sobre a realidade social por meio das ferramentas da política e do direito, como em uma cama de Procusto ${ }^{16}$. Em vez disso, era uma perspectiva segundo a qual as ciências sociais investigavam as condições e mecanismos para a construção de consensos entre as massas. Em suma, o cerne da questão era uma mudança da imposição de coerção para a organização de consenso. No meio, estava o surgimento de sociedades fundamentalmente "democráticas". Afinal, esse foi o desenvolvimento lógico do tipo de sociedade descrito por Tocqueville quase um século antes.

A conexão tocquevilliana da democracia e do aprisionamento ainda funcionou no século Xx? Na verdade, eu acho que sim. Talvez pudéssemos conciliar a ideia de projeto penitenciário, como projeto de transformação antropológica forçada da sociedade, com a de representação da majestade do Estado ${ }^{17}$ - as duas faces com que a prisão se apresenta, o que no início deste ensaio nós chamamos de a Bastilha e as bastilhas dos pobres. Provavelmente existe no início do caso americano - e ao con-

15. Os cafone do sul da Itália eram camponeses, tidos como simples, rudes e analfabetos. Após o processo de unificação do país, o termo passou a ser usado pejorativamente por setores sociais do norte, em alusão aos estratos sociais considerados mais atrasados do sul do país. Ver: https://michaelis.uol.com. $\mathrm{br} / \mathrm{palavra/dnGWw/cafone/.}$

16. Nota dos Tradutores: Procusto é um personagem da mitologia grega. Diz-que que Procusto era um bandido que vivia em uma floresta e possuía uma imensa cama. Todos os que passavam pela floresta eram presos e colocados por ele em sua cama. Daqueles que eram grandes demais, Procusto cortava os pés. Os que eram pequenos demais, eram esticados por Procusto. O padrão utilizado era o tamanho de sua cama.

17. Michael Ignatieff menciona a própria observação de Beaumont e Tocqueville sobre isso: "Enquanto a sociedade nos Estados Unidos dá o exemplo da liberdade mais extensa, as prisões do mesmo país oferecem o espetáculo do despotismo mais completo" (Beaumont \& Tocqueville 1833, p. 79, apud Ignatieff, 1978, p. 212). 
trário do que vimos na Europa do século XIX - a prevalência de uma ideia de prisão como tecido da ordem social em vez de mero simbolismo de poder, das bastilhas dos pobres sobre as da Bastilha. A prisão americana é um prenúncio da modernidade, pelo menos em seu conceito, ao invés da representação de um Estado forte. Esse conceito, parece-me, ainda é muito válido na era do encarceramento em massa, com sua crença implícita na eficácia generalizada da disciplina. Podemos entender o encarceramento em massa começando na década de 1970 ainda nesta visão de um projeto de transformação antropológica em massa, uma transformação antropológica em massa que estava reagindo à extensa "insurgência" dos anos 1960 - uma insurgência em massa que, especialmente entre estratos específicos da população, foi primeiro política e social e depois econômica. O que as duas faces da prisão certamente parecem ter em comum, porém, é a ideia da prisão como uma fábrica de subordinação (Melossi, 2020). A subordinação política - a Bastilha - é a premissa necessária, ao que parece, para a subordinação social e econômica - as bastilhas dos pobres.

Não há contradição, portanto, entre a "América" como "Estado de controle social" - como passei a chamá-la - e o uso extensivo da prisão, reativado cada vez que há um segmento da população que deve ser incorporado à máquina da sociedade - razão pela qual, em minha opinião, a reabilitação é a ideologia perene da prisão, seja ela perseguida na prática ou não. $\mathrm{O}$ encarceramento em massa estadunidense da segunda metade do século $\mathrm{xx}$ - e percebo que isso não é muito mais do que uma hipótese baseada no que eu disse até aqui - deve, portanto, ser visto como uma resposta à gigantesca migração de afro-americanos, nas décadas anteriores, dos estados do Sul para o Norte e para o Oeste, uma migração em massa que eventualmente, nas décadas de 1960 e 1970, foi um terreno fértil para uma insurgência estendida, com também, é claro, aspectos de subjetividade política notável (pensemos no Partido dos Panteras Negras, por exemplo). Se, nas décadas de 1960 e 1970 era possível encontrar vanguardas afro-americanas encarceradas em prisões escassamente povoadas, nos anos de encarceramento em massa o oposto era verdadeiro, e afro-americanos pobres e sem instrução do centro da cidade (filhos e sobrinhos dessas vanguardas) continuavam lá.

Da mesma forma, hoje na Europa, quando uma nova massa de migrantes veio para reabastecer as fileiras dos estratos mais baixos da classe trabalhadora, as sociedades europeias não fizeram nada menos do que tratar os imigrantes como estavam acostumados a tratar os mais desfavorecidos entre os seus - algo que se tornou difícil de fazer após a militância dos trabalhadores das décadas de 1960 e 1970 (Melossi, $2018)^{18}$. Podemos entender, portanto, o aparente paradoxo que Massimo e eu ti-

18. Daí, o brilhantismo de um migrante africano da Costa do Marfim, Aboubakar Soumahoro (2019), 
vemos que enfrentar quando, no início dos anos 1970, começamos a pensar sobre a prisão na Itália. Os baixos níveis de encarceramento que estávamos descobrindo por volta do início dos anos 1970 - apesar do grito de “repressão, repressão!” ao nosso redor - níveis que, no entanto, eram caracterizados por um bom número de militantes políticos e sindicais, foram substituídos agora por um encarceramento em massa de migrantes (e outros). O processo de globalização gentilmente ofereceu aos capitalistas italianos (e outros) o tipo de força de trabalho dócil que eles perderam entre os anos 1960 e 1970. Como já havia acontecido antes, essa força de trabalho dócil era aquela destinada a ser processada nas bastilhas dos pobres. Na verdade, a ideia de que as Bastilhas eram destinadas à supressão das vanguardas da classe trabalhadora pode estar correta. É a supressão das vanguardas que mais tarde abre a possibilidade de encher as bastilhas dos pobres com as fileiras de um exército de reserva de trabalho convocado de muito longe - uma vez que a oposição dos rebeldes políticos, oponentes e lideranças tinha sido eliminada. Nenhuma conspiração se destina a tal concatenação de eventos. Simplesmente o caminho bem cavado daquela velha toupeira, a luta de classes.

\section{Conclusões: Bastilha e bastilhas}

A Bastilha e as bastilhas dos pobres podem estar menos em oposição do que assumimos no início deste ensaio. Seguindo a lógica dos longos ciclos econômicos, retratada na Figura 1, no auge do desenvolvimento econômico e dos conflitos sociais, como nos anos de 1920 ou 1970, ocorreram eventos de forte conflito social - geralmente desencadeados pela força da classe trabalhadora no mercado de trabalho e na sociedade em geral - que encontraram expressão em forte repressão política, mas que mantiveram as celas de prisão vazias para seus clientes costumeiros. Mais tarde, porém, em um equilíbrio político restabelecido - dominado pelo poder do capital (privado ou público) -, o recrutamento de novas fileiras no exército dos despossuídos exige aquela enorme máquina de processamento, que é o conjunto de instrumentos panópticos, na prisão primus. Dentro de uma mesma sociedade, portanto, as prisões podem passar de uma função de repressão política para a função que sempre foi a mais parecida com a prisão moderna, um projeto de transformação antropológica, de acordo com as necessidades das relações de classe e alinhamento político.

que está tentando organizar os "refugiados" africanos - a força de trabalho nos campos do sul da Itália hoje, resgatando-os da guetização e do trabalho "escravo", e que, em seus discursos e escritos, continua fazendo referência aos feitos do famoso sindicalista comunista Giuseppe Di Vittorio, um grande organizador dos trabalhadores sulistas na primeira metade do século Xx. 
Portanto, não há razão para que as democracias não possam alimentar o encarceramento em massa - como no caso dos Estados Unidos ou do Brasil. De fato, se pensarmos que uma das vocações das democracias é o desenvolvimento econômico, como pode ter sido o caso do Brasil nas últimas décadas ${ }^{19}$, essas vocações significam uma gigantesca transformação social de uma economia de subsistência para uma economia de mercado. Esse é exatamente o tipo de mudança de estrutura social que, no entanto, está geralmente ligado ao desenvolvimento do encarceramento. A função específica das bastilhas dos pobres é a de produzir "máquinas republicanas" (e trabalhadores dóceis), segundo Benjamin Rush. Contudo, dentre os dois termos, a "máquina” geralmente pode levar vantagem sobre o "republicano". Não esqueçamos a máxima a partir da qual Georg Rusche deu os primeiros passos para a sua análise seminal, a ideia de que "o direito penal e o trabalho diário dos tribunais criminais são dirigidos quase exclusivamente contra aquelas pessoas cuja origem de classe, pobreza, educação negligenciada ou desmoralização os levaram ao crime" (Rusche, 1933, p. 3) - um "universal criminológico", se houver! Para "aquela gente", o trabalho de transformação antropológica da prisão, tanto no projeto como na realidade prisional, é essencialmente de ensino da obediência e da subordinação. A subordinação - não nos esqueçamos - é o denominador menos comum do trabalho (Melossi, 2020). Esse é particularmente o caso daquela "classe" de homens que cometem os crimes "de pobreza e desespero, o crime daquele infeliz setor de homens para quem o talvez 'terrível' e 'desnecessário' direito de propriedade não permitiu nada além de uma existência” (Beccaria, 1764, tradução minha). Máquinas republicanas, cidadãos perfeitos e bons trabalhadores! A prerrogativa primeira desses cidadãos perfeitos e bons trabalhadores, porém, é a obediência à lei e a subordinação ao senhor, e a democracia não é exceção! Como Marx e Foucault apontaram, a tirania nas moradas de produção é a face oculta "das liberdades jurídicas formais" na superfície (Foucault, 1975, p. 222). As funções da Bastilha e das bastilhas dos pobres talvez sejam diferentes, mas não há contradição entre elas!

19. Sobre o Brasil, ver Fonseca (2018). Outro caso recente crucial é, claro, a China! (ver Shen, 2018). 


\section{Referências Bibliográficas}

Beaumont, Gustave de \& Tocqueville, Alexis de. (1833), On the penitentiary system in the United States and its application in France. Carbondale/Edwardsville, Southern Illinois University Press, 1964.

Beccaria, Cesare. ([1764] 1999), Dos delitos e das penas. São Paulo, Revista dos Tribunais.

Dumm, Thomas L. (1987), Democracy and punishment: disciplinary origins of the United States. Madison, The University of Wisconsin Press.

Durkheim, Émile. ([1950] 2015), Leçons de sociologie. Présentation par Serge Paugam; avant-propos de Hüseyin Nail Kubali; introduction de Georges Davy. Paris, Presses Universitaires de France. Ed. bras.: (2002), Lições de sociologia. Tradução de Monica Stahel. São Paulo, Martins Fontes.

Durkheim, Émile. ([1898-1900] 1958), Professional ethics and civic morals. Glencoe, Free Press, 1958.

Federn, Paul (1919), “Zuer Psychologie der Revolution: die vaterlose Gesellschaft”. Der Oesterreichische Volkswirt, 11: 571-574, 595-598.

Fonseca, David S. (2018), "Expansion, standardization, and densification of the criminal justice apparatus: Recent developments in Brazil”. Punishment and Society, 20: 329-350.

Foucault, Michel. ([1975] 1977), Discipline and punish: the birth of the prison. Nova York, Pantheon. Ed. bras.: FouCAult, Michel. (2009), Vigiar e punir: nascimento da prisão. São Paulo, Editora Vozes.

Foucault, Michel. (1978), "Governmentality”. Ideology and Consciousness 6: 5-21.

Freud, Sigmund. ([1913] 1955), Totem and taboo. In: The standard edition. Londres, Hogarth, vol. 13, pp.1-161.

Freud, Sigmund. ([1921] 1955), Group psychology and the analysis of the ego. In: The standard edition. Londres, Hogarth, vol. 18, pp. 65-141

Freud, Sigmund. ([1930] 1961), Civilization and its discontents. In: The standard edition. Londres, Hogarth, vol. 21, pp. 57-146.

Freud, Sigmund. ([1933] 1964), New introductory lectures on psychoanalysis. In: The standard edition. Londres, Hogarth, vol. 22, pp. 1-182.

Freud, Sigmund. (2019), Edição standard brasileira das Obras psicológicas completas de Sigmund Freud, vol. XIx: O ego e o id, e outros trabalhos (1923-1925), eBook Kindle.

Freud, Sigmund. ([1932, 1933] 1996), "Conferência XXXI: a dissecção da personalidade psíquica". In: Edição standard brasileira das Obras psicológicas completas de Sigmund Freud. Rio de Janeiro, Imago, vol. 22.

Grandi, Dino. (1941), Bonifica umana. Two volumes. Roma, Ministero di Grazia e Giustizia. Horkheimer, Max \& Adorno, Theodor W. (1944), Dialectic of Enlightenment. Nova York, Continuum, 1989. 
IgNATIEFF, Michael. (1978), A just measure of pain. Londres, Macmillan.

Jellinek, Georg. ([1895] 1901), The Declaration of the Rights of Men and Citizens. Nova York, Holt.

Kelsen, Hans. ([1922] 1924), "The conception of the state and social psychology”. The International Journal of Psychoanalysis, 5: 1-38 (German original in "Der Begriff der/s Staates und die Sozialpsychologie", Imago, 8: 97-141).

LaCAN, Jacques. (1998), “A coisa freudiana”. In. Écrits. Rio de Janeiro, Zahar.

Marx, Karl. (2010), Crítica da Filosofia do Direito de Hegel. São Paulo, Boitempo.

MeAd, George H. (1925), "The genesis of the self and social control”. In: Mead, G. H. Selected writings. Indianapolis, Bobbs-Merrill, 1964, pp. 267-293.

Melossi, Dario. (2020), "Prison, subordination, inequality: again on a marxist perspective”. In: Lacey, N.; Soskice, D.; Cheliotis, L. K. \& Xenakis, S. (eds.). Tracing the relationship between inequality, crime and punishment: space, time and politics. Oxford, Oxford University Press/British Academy.

Melossi, Dario. (2018), "The prison and the factory revisited (2017): Penality and the critique of political economy between Marx and Foucault”. In: Melossi, Dario \& Pavarini, Massimo. The prison and the factory (40th anniversary edition): Origins of the penitentiary system. Londres, Palgrave Macmillan, pp. 1-24.

Melossi, Dario. (2008), Controlar el delito, controlar la sociedad: Teorias y debates sobre la cuestion criminal, del siglo XVIII al XXI. Buenos Aires, Siglo Veintiuno.

MeLossi, Dario. (1990), The state of social control: a sociological study of concepts of state and social control in the making of democracy. Cambridge (UK)/Nova York, Polity Press/St. Martin's Press.

Melossi, Dario \& Pavarini, Massimo. (2006), Cárcere e fábrica: as origens do sistema penitenciário (séculos XVI-XIX). Rio de Janeiro, Revan.

Pateman, Carole. (1988), The sexual contract. Cambridge, Polity press.

Paz, Octavio. ([1979] 1985), "Mexico and the United States". In: PAz, O. The labyrinth of solitude. Londres, Penguin Books, pp. 355-376.

Rusche, Georg. (1933), "Labor market and penal sanction”. Crime and Social Justice 10: 2-8.

Rusche, Georg \& Kirchheimer, Otto. ([1939] 2003), Punishment and social structure. New Brunswick (NJ), Transaction Publishers.

SHEN, Anqi. (2018), Internal migration, crime, and punishment in contemporary China. Cham. Springer.

Soumahoro, Aboubakar. (2019), Umanità in rivolta. La nostra lotta per il lavoro e il diritto alla felicità. Milão, Feltrinelli.

TETI, Vito. (1993), La razza maledetta: origini del pregiudizio antimeridionale. Roma, manifestolibri.

Toceueville, Alexis de. ([1835-1840] 1961), Democracy in America. Two volumes. Nova York, Schocken. 
Weber, Max. ([1904-1905] 1958). The protestant ethic and the spirit of capitalism. Nova York, Scribner's.

\section{Resumo}

Bastilhas de pobres e prisões da democracia: Uma reflexão sobre um trade-off entre liberdade e (auto)controle

Este ensaio pretende analisar a relação entre luta de classes e prisão a partir de duas de suas dimensões nas sociedades modernas: como mecanismo repressivo que opera contra vanguardas políticas e como mecanismo produtor de disciplina sobre amplas camadas sociais, mais especificamente, as classes despossuídas. Para cumprir este objetivo, recorremos à imagem da bastilha tradicional, para ilustrar a primeira dimensão, e da bastilha dos pobres, para nos referirmos à segunda. As bastilhas dos pobres se constituíram como meio de transformação antropológica do povo, fortemente vinculadas a uma ideia de democracia como autogoverno. $\mathrm{O}$ autocontrole, a ser adquirido na prisão, estava inerentemente vinculado ao autogoverno da democracia, como em um trade-off. Esse foi o caso na elaboração do Iluminismo, dos Quakers do século XVII a Beccaria e ao Panóptico de Bentham. O caso dos Estados Unidos é exemplar nesse sentido, pois nos permite compreender a relação entre o autocontrole, inscrito no projeto da disciplina prisional, e o autogoverno, como livre exercício da cidadania política.

Palavras-chave: Prisões; Autocontrole; Autogoverno; Democracia.

\section{Abstract}

Poor people's Bastilles and democracy's prisons: A reflection about a "trade-off" between liberty and (self-) control

This essay intends to analyze the relationship between class struggle and prison from two dimensions in modern societies: as a repressive mechanism that operates against political vanguards and as a mechanism that produces discipline over broad social strata, more specifically the dispossessed classes. To fulfill this objective, we use the image of the traditional Bastille, to illustrate the first dimension, and the poor people's bastilles, to refer to the second. Poor people's bastilles were constituted as a means of anthropological transformation of the people strongly linked to an idea of democracy as self-government. The self-control to be acquired in prison was inherently tied to the self-government of democracy, as in a "trade-off". This was the case in the elaboration of the Enlightenment, from seventeenth-century Quakers to Beccaria to Bentham's Panopticon. The case of the USA is exemplary in this sense, as it allows us to understand the relationship between self-control, inscribed in the project of prison discipline, and self-government, as the free exercise of political citizenship.

Keywords: Prisons; Self-control; Self-government; Democracy. 
Texto recebido em 16/10/2020 e aprovado em 28/10/2020.

DOI: 10.11606/0103-2070.ts.2020.176240.

DARIO Melossi é professor alma mater da Universidade de Bolonha e distinguished affiliated scholar do Center for the Study of Law and Society, da Universidade da Califórnia/Berkley. Depois do bacharelado em Direito, na Universidade de Bolonha e do doutorado em Sociologia na Universidade da Califórnia/Santa Bárbara, foi professor associado da Universidade da Califórnia/ Davis, até que nos anos de 1990 voltou para Bolonha. Publicou Cárcere e fábrica: as origens do sistema penitenciário (séculos XVI-XIX) (1977, junto com Massimo Pavarini), The state of social control: A sociological study of concepts of state and social control in the making of democracy (1990) e Controlling crime, controlling society: thinking about crime in Europe and America (2008). Além disso, tem mais de duzentas outras publicações. Foi editor da revista Punishment and Society e agora é editor chefe do European Journal of Criminology. Em 2007 recebeu o International Scholarship Prize da Law and Society Association e em 2014 o European Criminology Award da Sociedade Europeia de Criminologia. Seu livro mais recente é Crime, punishment and migration (2015). Suas pesquisas em andamento dizem respeito ao processo de construção do desvio e do controle social na União Europeia, especialmente em relação aos processos migratórios. E-mail: dario.melossi@unibo.it. 